Guest Editorial, part of a Special Feature on Exploring Social-Ecological Resilience through the Lens of the Social Sciences: Contributions, Critical Reflections, and Constructive Debate

\title{
Expanding the contribution of the social sciences to social-ecological resilience research
}

\author{
Samantha Stone-Jovicich $^{1}$, Bruce E. Goldstein ${ }^{2}$, Katrina Brown $^{3}$, Ryan Plummer $^{4}$ and Per Olsson $^{5}$
}

Key Words: human agency; participatory methods; power; qualitative research; reflexivity; social change; social-ecological systems; social sciences; transdisciplinary; transformation

\section{INTRODUCTION}

As we are confronted with mounting evidence of the profound and potentially irreversible impacts of human activities on the planet - encapsulated in the notion of the Anthropocene- the need to engage across a range of ways of knowing and doing becomes increasingly urgent. The intersection and interdependence of human-environment systems is seen by scholars, policy makers, and other stakeholders as providing a promising vehicle for bridging understandings and guiding actions toward a more sustainable future (Berkes and Folke 1998, Berkes et al. 2008). Growing attention is thus being focused on social-ecological resilience. Indeed, it is increasingly being adopted as a centerpiece of policy making, planning processes, and management strategies (e.g., Field et al. 2014; http://www.100resilientcities.org). It also is being embraced in other fora - such as civil society and social movements (e.g., the Transition Movement) and in arts and creative practice - as a means to invoke and provoke critical reflection and debates about society directions and alternative visions (e.g., Rathwell and Armitage 2016, Brown et al. 2017; https://transitionnetwork.org).

The effectiveness of social-ecological resilience in informing transitions to more sustainable futures and actions depends on an understanding of biophysical, environmental, and human systems. There is widespread agreement that we need integrative research that transcends disciplinary boundaries and embraces ideas from the natural and social sciences, as well as other bodies of knowledge (e.g., Castree et al. 2014, Brondizio et al. 2016). This is not new to social-ecological resilience. Over the past decade, the field has taken a "social turn" (Brown 2013) as resilience researchers broadened their theoretical and methodological lens to incorporate insights and approaches from a wide range of non-natural science disciplines: from the social and behavioral sciences (e.g., sociology, anthropology, human geography, economics, psychology) to closely aligned interdisciplinary fields (e.g., sustainability sciences, global environmental change sciences, environmental education, architecture, planning, law) and, to some extent, the humanities (e.g., literature, philosophy, religion, arts, and music). The field also has widened its concept of what are credible knowledge practices, expanding from a positivist tradition of scientific inquiry to interpretive and participatory modes of research (e.g., Fazey et al. 2018). This crossdisciplinary engagement has gained momentum over the years, as evidenced in the expansion in number and scope of integrative work presented at the Resilience conferences since 2008 (see Bousquet et al. 2016) and related publications.

This Special Feature emerged in response to this mounting crossdisciplinary appetite and the opportunity to open up a discussion about how and in what ways this collaboration can be strengthened moving forward. The main premise that underpins the collection of papers in the Special Feature is that enriching this engagement across disciplines necessitates transcending traditional approaches to integration, which tacitly give the social sciences a "service" role, i.e., "being allowed to observe what they do but not disturb it" (Viseu 2015). Incorporating descriptive and analytical research to improve understanding of the human and social dimensions that influence the functioning and sustainability of Earth systems remains vital. Nonetheless, meaningful and productive crossdisciplinary collaboration requires also making room for "disruptive, reflexive, generative, innovative, and instrumental" roles and approaches (Popa et al. 2015, Bennett et al. 2017a, b). These are critical to effectively address our planet's most "wicked" problems such as climate change, food security, and poverty as divergences and dissension help foster the debates that are central to the creation of new ideas and possible "solutions" (Hirsch Hadorn et al. 2006, Brown et al. 2010). Thus, providing space for constructively exploring divergent perspectives, tensions, and discordances - as well as a willingness to be reflexive - is integral to furthering a fruitful engagement between the social sciences (and other bodies of knowledge) and social-ecological resilience research.

\section{PAPER CONTRIBUTIONS}

In line with the above, the papers in this Special Feature stretch the ways in which the social sciences can engage with/in socialecological resilience. They do so in two ways: by integrating longstanding social science theories, concepts, and methodologies into current social-ecological resilience frameworks and concepts, and/or by bringing in theoretical lenses and approaches-some relatively nascent and contentious even within the social sciences - that challenge resilience thinking, research, and practice. In pursuing the former, papers illustrate the potential for stronger crossdisciplinary synergies by exploring how specific bodies of social science knowledge and research practice can enrich resilience analyses. The papers that wrestle with conceptual and methodological tensions and incompatibilities highlight possible avenues for new ways of thinking about not only social-ecological resilience but also about how different disciplines and fields can

${ }^{1}$ CSIRO Land and Water, CSIRO, Australia, ${ }^{2}$ Programs in Environmental Design and Environmental Studies, University of Colorado, Boulder, Colorado, USA, ${ }^{3}$ Geography, University of Exeter, UK, ${ }^{4}$ Environmental Sustainability Research Centre, Brock University, St. Catharines, Ontario, Canada, ${ }^{5}$ Stockholm Resilience Centre, Stockholm University, Sweden 
enrich each other. They encourage crossdisciplinary risk taking and "thinking out of the box" and, in doing so, pave the way for creative and innovative actions needed for a more sustainable future.

In the paper by Hobman and Walker (2015), insights from psychology are incorporated to improve understanding of change and social-ecological resilience. They combine Lewin's 1950s Field Theory, a theoretical perspective that explicitly used the concept of social-ecological systems and aimed to better understand and effect change, with more recent contributions from ecological, cognitive, and social psychology and sustainability sciences. The crossdisciplinary conceptual framework they develop provides a means to better understand human and social dimensions of change and resilience from the intersection between psychological elements (i.e., how actors in the system perceive their environment) and their "objective" surroundings (i.e., the physical and social environment that enables or constrains people's behaviors). They demonstrate how we can gain a better understanding of these interlinkages and interdependencies, at particular points in time and places, and how this understanding can help inform actions for transformational change toward more resilient social-ecological systems (SESs).

The paper by Bush and Marschke (2014) considers socialecological change in the context of aquaculture from two distinct perspectives on social change - agrarian change and sociotechnical transition theory. The authors illustrate how these two theoretical perspectives, which have a long and rich tradition in social science scholarship, provide different insights into understanding the complexity and multiscale aspects of social and environmental transition in the aquaculture sector, and social-ecological change more broadly. In particular, they demonstrate how these bring insights about aspects of social change that tend to be understudied in resilience thinking: the situated and political aspects of change processes and the role of sociotechnical networks in fostering innovation for sustainability. Agrarian change theory, through its focus on indepth empirical case studies that look at the situated intricacies of local agency and social relationships of power and control, "opens up questions of material power and control over the environment that contrast with the questions of risk, vulnerability, and uncertainty that resilience thinking examines through coupled social-ecological systems." Sociotechnical transition theory focuses on understanding processes of change in terms of innovation in sociotechnical networks. The authors also demonstrate how three theoretical perspectives (resilience thinking, agrarian reform, and transition theory) that do not share the same ontological and epistemological foundations can nonetheless be constructively complemented to provide a richer and "more robust assessment of the social aspects of social-ecological transitions in the aquaculture sector and beyond."

Moore et al. (2014) shed light on deliberative transformations of linked social-ecological systems. They argue that research on and practical efforts to intentionally transform systems toward more sustainable trajectories for people and the environment tend to emphasize either the social or ecological dimensions rather than their coupled nature. They propose a framework that draws on previous analyses of transformations in SESs and insights from three bodies of social science literature on radical change (social movements, sociotechnical transitions, and social innovations). The framework bridges social and ecological understandings of transformation and outlines the processes and phases of transformative change in an SES. It provides an avenue for analyzing the alteration of social-ecological feedbacks, critical barriers and leverage points, and outcomes of social-ecological transformations.

The paper by Apgar et al. (2015) on the Guna indigenous people illustrates the importance of considering cultural and spiritual dimensions of adaptation, transformation, and social-ecological resilience. They show how longstanding social and cultural processes have created enabling conditions that have fostered the Guna people's adaptive and transformational capacity. Furthermore, they highlight how a participatory action research (PAR) approach and process enabled a collaborative process of inquiry. They also demonstrate the value of inductive, qualitative research methods - sparingly used in social-ecological resilience research - can provide rigorous scientific insights.

The paper by Gray et al. (2015) explores the value of participatory methods for integrating individual, community-level, and expert knowledge and for developing models of SESs that are driven by stakeholders and support communities. They introduce fuzzy cognitive mapping (FCM), a participatory modeling approach that has been used in a range of contexts, including fisheries management and agriculture, but less so in resilience-informed research and assessments. Through a case study of bushmeat trade in Tanzania, the authors demonstrate how FCM can be used as a tool and process for promoting resilience analysis among stakeholders by identifying key state variables that comprise an SES, evaluating alternative SES equilibrium states, and defining desirable or undesirable state outcomes through scenario analysis.

The paper by Tidball (2014) examines the role of social-ecological symbols in three postdisaster case studies in the USA (New York 2001 terrorist attack, New Orleans 2005 hurricane Katrina, and tornado-torn Joplin, Missouri in 2011). He highlights the importance of the symbol of the tree and the ritual of tree planting in situations where the SES has undergone large-scale shocks. His study of tree symbols and tree planting rituals adds to a growing body of work within resilience studies on the role of material and nonmaterial cultural dimensions of social-ecological resilience. To this, he adds another perspective, that of hybrid socialecological symbols or symbols that "contain both social and ecological meanings, and also, more importantly, social and ecological interactions." He demonstrates the importance of the presence of these hybrid tree symbols and tree planting rituals to the process of recovering from specific disasters and to enhancing and perpetuating resilience postdisaster.

Dwiartama and Rosin (2014) endeavor to unpack the notion of "actors" and "agency" in SESs and their role in enhancing resilience from the perspective of Actor-Network Theory (ANT). Through an analysis of two case studies - one on Indonesian rice production systems and the other on New Zealand kiwifruitthey demonstrate how ANT's encompassing conceptualizations of agency can enhance awareness and understanding of the intertwined role of humans and nonhumans in influencing the configuration of SESs and building resilience. They argue that 
enhancing understanding of human and societal adaptive capacity and resilience requires extending the focus from individual humans to the wider network of human and nonhuman actors (or "actants" in ANT terminology) in the system and how their interactions shape, challenge, and constrain ability to influence, change, and build resilience.

The paper by Stone-Jovicich (2015) also explores the value of ANT for extending social-ecological resilience thinking and practice, in addition to two other social science perspectivesmaterio-spatial world systems analysis and critical realist political ecology. She provides examples of how social science theoretical perspectives with very different underpinning ontological and epistemological foundations can foster stronger inter- and transdisciplinary ties with social-ecological resilience. She demonstrates how materio-spatial world systems analysis offers the potential to enrich resilience analyses of global environmental change, global governance and stewardship, planetary boundaries, and multiscale resilience. She highlights the role critical realist political ecology perspectives can play in supporting resilience research to integrate greater consideration of local/ traditional/indigenous knowledge systems and power, and to consider the normative assumptions in social-ecological resilience. The value of ANT is argued to be its potential to understand and analyze resilience as "resilience-in-the-making," which offers both new insights but also challenges the boundaries of resilience thinking and practices.

The focus of Fabinyi et al.'s (2014) paper is unpacking the "social" and power in SESs and demonstrating how more nuanced framings of these dimensions can help inform social-ecological resilience analyses. They argue the need to move beyond organized social units and institutional perspectives to understanding the complexity and diversity inherent in society and among people. They draw on perspectives from ecological and social anthropology and political ecology to focus a multi- and interdisciplinary lens on social differentiation and power and to draw attention to issues of competing goals, differences in perspectives and experiences, and contested interests. They build on these social science bodies of work to propose how social diversity and power can be better integrated in understandings of human-environment relationships, SESs, and social-ecological resilience research.

The issue of power is also the central focus of the paper by Boonstra (2016). Responding to the need for greater understanding of power relationships, injustices, and inequities in social-ecological resilience research, he reviews and synthesizes how power-its sources and dimensions-have been conceptualized in social science theory. He uses that as a foundation to develop a conceptualization of power that can be applied to better understand how power mediates and shapes social-ecological interactions and resilience. In his framework, power is presented as comprising dimensions that shape both the conduct and context of societies and ecological systems. The process of domestication of fire thousands of years ago is provided as an example of how hominids used fire as a source of power that irreversibly restructured the way humans relate to their environments and to each other.

\section{KEY INSIGHTS AND EMERGING FRONTIERS}

All of the papers in this Special Feature demonstrate how different social science disciplines, theories, concepts, and methodologies can deepen knowledge of the social and human dimensions of social-ecological resilience and support actions toward a more sustainable future. We discuss some of the key insights that emerge from the papers and reflect on the future of social science and broader crossdisciplinary contributions in the field.

\section{Human and social dimensions of change, transitions, and transformations in the context of social-ecological systems and resilience}

All of the papers provide, implicitly or explicitly, insights on the dynamics of social change in linked human-environment systems and how these shape groups' and societies' paths toward enhanced resilience. What stands out is that there exists a rich variety of perspectives from the social (and behavioral) sciences that have yet to be fully explored in the realm of social-ecological resilience. Some of these span theories and methodologies that are well recognized and extensively applied within their respective fields. For example, the paper by Hobman and Walker (2015) demonstrates the value of reaching back to earlier pieces of intellectual work. The authors remind us that social psychology has a long history of engagement with concepts of SESs and resilience. Their articulation of the classical literature of Kurt Lewin (1890-1947) with current social-ecological understandings of resilience offers a new way of understanding not only change in coupled human-environment systems but also the link between individual, group, and system loci of change. Bush and Marschke's (2014) blend of a long-established theoretical framework (agrarian change theory) with a more recent perspective (sociotechnical theory) articulates previously understudied aspects (situated and political aspects of change processes and the role of sociotechnical networks in fostering innovation for sustainability) of social change dynamics in socialecological transitions. These papers, among others in this Special Feature (e.g., Moore et al. 2014, Stone-Jovicich 2015), demonstrate the relevance and applicability of established bodies of social and behavioral science knowledge for advancing analyses of change in social-ecological resilience. Other papers challenge us to consider perspectives on change that, at first glance, do not seem to be compatible with social-ecological resilience. The Actor Network Theory (ANT)-informed papers by Dwiartama and Rosin (2014) and Stone-Jovicich (2015) extend our understanding of how change and resilience unfold through the lens of a world in which the notion of the "social" does not exist other than as an intertwined and dynamic network of human and nonhuman actors. This view of change-via-hybridity is also explored in Tidball's (2014) paper. The author highlights how tree symbols and tree planting rituals, which are viewed as containing both ecological and social meanings and interactions, are instrumental to catalyzing change in postdisaster contexts toward enhanced community resilience.

\section{The role of human and nonhuman actors and agency in influencing change and resilience}

The role of actors and agency in shaping SESs and building resilience is an area that has been highlighted as in need of further exploration (Davidson 2010, Brown and Westaway 2011). As in the case of analyses around social change, transitions, and transformation, there is a rich array of social science theories and 
methodological approaches that have much to offer in way of deepening understanding of the notion of agency and the role that different actors play. To date, the majority of social science perspectives that have been integrated in social-ecological resilience have focused on human actors. Some of the papers in this Special Feature introduce theories and methodologies that emphasize nonhuman actors, such as trees, rivers, and technologies, and how they interact with people in shaping SESs and capacity for change and resilience. Dwiartama and Rosin (2014) and Stone-Jovicich (2015) demonstrate this through their application of ANT, and Tidball (2014) through his analysis of hybrid social-ecological symbols. Although these papers are exploratory (particularly the first two) they reveal that, despite significantly different epistemological and ontological foundations, "hybrid" perspectives and social-ecological resilience thinking can be brought together into constructive dialogs that yield new and creative insights and lines of inquiry.

\section{The contribution of material and nonmaterial cultural and social dimensions to enhancing resilience at individual, community, and system scales}

Researchers and practitioners engaging with social-ecological resilience ideas and practices have long recognized the role sociocultural processes (e.g., arts festivals, indigenous rituals) and knowledge (e.g., traditional ecological knowledge) play in shaping SESs and contributing to resilience (Berkes and Folke 1998, Davidson-Hunt and Berkes 2003, Folke 2004, Moller et al. 2004). The social sciences are well placed to further contribute to this area of inquiry. There are opportunities for further engagement with disciplines within the social sciences that have a long and rich history of work in this area, such as anthropology. The paper by Apgar et al. (2015) is an example of the value of such an integration. Through their application of qualitative and participatory methodologies extensively used in the field of anthropology, they are able to provide a rich understanding of the role of cultural practices and institutions in facilitating the Guna people's capacity to adapt and be more resilient both at a community and individual level. Tidball's (2014) case studies in New York City, New Orleans, and Joplin, Missouri remind us, however, that material and nonmaterial symbols and rituals also play an important role in enhancing resilience in Western countries and urban contexts. His study of tree symbols and treeplanting rituals joins other social-ecological resilience studies that explore the role of culture-including theatre, music, and the visual arts - in supporting people and societies to articulate visions and build sustainable pathways (e.g., Bjordam 2012, Goldstein 2012, Brown et al. 2017).

\section{Power relationships, dynamics, and inequity in resilience}

Issues of power and inequity have been longstanding and central foci of social science research and scholarship. Although not entirely neglected in social-ecological resilience research, there remains a limited understanding of matters of power and conflict and their implications for the way social-ecological resilience is framed and practiced (Evans 2011, Phelan et al. 2012, Wilkinson 2012, Hahn and Nykvist 2017). Several of the papers in this Special Feature draw on well-established theories to fill in some of these gaps. In providing multiple understandings of how power is expressed, they highlight the importance of integrating more nuanced analytical lenses if social-ecological resilience is to effectively contribute to a more socially just and desired future.
For example, Stone-Jovicich's (2016) incorporation of world systems analysis, critical realist political ecology perspective, and ANT reveal very different concepts of how power is formed and shapes people and the SESs in which they are embedded. The framework proposed by Boonstra (2016), on the other hand, builds on and integrates different strands of social theory on power to offer new ways of thinking about and analyzing power in social-ecological systems. Whether building on existing bodies of literature or providing new framings, each of these theoretical lenses proposes quite distinct avenues for how inequities can be addressed and resilience can be built. However, as Fabinyi et al. (2014) remind us, understanding power, inequity, and implications for social-ecological resilience is contingent on first unpacking what is meant by the "social" to reveal diversity and differences.

\section{Qualitative and participatory methodologies}

Although a core strand of the social sciences, qualitative and participatory methodologies remain underused in socialecological resilience research. Three papers in the Special Feature highlight the value these approaches, and the data generated through their application, to building more robust and inclusive social-ecological resilience framings and practices as a result of incorporating different perspectives, values, and knowledge systems. Apgar et al.'s (2015) study of the Guna people in Panama demonstrates how a participatory action research (PAR) approach, complemented by ethnographic methods, led to a collaborative process of inquiry. They also highlight how inductive, qualitative research methods can provide rigorous data via triangulation of methods (PAR, ethnographic methods, literature reviews) and data (use of both primary and secondary data), and the application of grounded theory as a systematic qualitative data analysis method. The contribution of ethnographic field work to opening up new ways of seeing and analyzing resilience is also demonstrated by Tidball's (2014) postdisaster case studies in the USA. By capturing stories and recording memorials and acts of replanting, the author is able to examine the symbolic role of trees and tree planting in enhancing disaster recovery. Gray et al. (2015) introduce a different participatory method for understanding SESs: fuzzy cognitive mapping (FCM). In a case study of bushmeat trade in Tanzania, FCM is used collaboratively to analyze the SES and applied with scenario analysis to identify desirable and undesirable future states.

\section{Multi-, inter-, and transdisciplinary exchange, collaboration, and integration}

Finally, all of the papers offer insights into the core theme of this Special Feature: how crossdisciplinary exchange between the social sciences and social-ecological thinking, and other bodies of knowledge, can be broadened beyond approaches that result in social science being "added-on to an already defined agenda" (Krauss 2015). The papers, as a collective, demonstrate that working between and among disciplines (i.e., multi-, inter-, and transdisciplinary) is possible and valuable. It also can take many shapes and forms. For example, Bush and Marschke (2014) propose a complementary or collaborative approach. They argue that ontological and epistemological differences between social science theories such as agrarian change and transition theory and social-ecological resilience require moving away from an integration approach to interdisciplinarity. Otherwise, this, they 
maintain, risks social theory and concepts being "naturalized" to fit into resilience thinking. Rather, they propose that concepts and methodologies are complemented, such as positivist approaches in resilience and transition theory and the qualitative hermeneutics in agrarian change theory, in such a way that interdisciplinary exchange is fostered through the sharing of "bridging" results and insights. In a similar vein, Fabinyi et al. (2014) emphasize moving away from attempts "to present one view of how the 'social' can be better conceptualized in an improved 'model' of an SES." Rather than pursuing interdisciplinarity in the name of building a "theory of everything" by integrating social theories into an overarching "grand narrative," they suggest a more productive, pragmatic, and realistic aim is to focus on the "more humble goal of simply fostering more genuine interdisciplinary dialogue." This involves acknowledging and accepting divergent views and perspectives and learning from how other disciplines and fields have approached similar conceptual challenges that social-ecological resilience thinking is grappling with.

\section{CONCLUSION}

Strengthening dialog and joint initiatives among the social sciences, social-ecological resilience and other bodies of knowledge is paramount for informing transitions to more sustainable actions and futures. This Special Feature is intended as a first conversation; a starting point. There is great potential to further support and grow this nascent collaboration. One way forward is to continue the crossfertilization of scientific thinking and methods. As demonstrated in a number of the papers in this Special Feature, social scientists can continue to take the lead in demonstrating the ways in which different theoretical perspectives and methodologies, from a rich array of subfields and schools of thought, improve understanding of the complex ways people and society interact with nature and the planet. At the same time, there is a need to look beyond these conventional "descriptive and diagnostic" contributions and tap into social sciences" "disruptive, reflexive, generative, innovative, and instrumental roles" (Bennett et al. 2017a). Supporting joint exploration of novel, blended, and unusual perspectives and approaches provides a unique opportunity to ensure that social-ecological thinking, research, and practice remain meaningful and effective.

Having said that, we recognize that translating the above into tangible and productive crossdisciplinary relationships and practices is challenging. Efforts in related interdisciplinary fields, such as the conservation sciences, demonstrate the extent to which engagement within and across the natural and social sciences tends to be fragmented and superficial (Bennett et al. 2017b). The role social science can play in informing viable future trajectories is not only often misunderstood by scholars who sit outside those fields (Bennett et al. 2017b), it is also internally contested among social scientists. Aside from philosophical divides among the life, physical, and social sciences, there exist deep-rooted competing ontological and epistemological assumptions, emphases, and understandings of society-environment interactions within the social sciences (see Miller et al. 2008, ISSC/UNESCO 2013, Leyshon 2014, Moon and Blackman 2014). In addition, some social scientists have raised serious concerns and reservations about the concept of social-ecological resilience, citing limited or narrow analysis of the role of power, social diversity, and human agency, among other social and human dimensions (Cote and
Nightingale 2012, Hatt 2013, Olsson et al. 2015). Others have been sceptical of the constructive potential of engaging with certain theoretical strands within the social sciences, such as critical theory and postmodernist approaches.

One step to overcoming the above challenges and to move toward more fruitful collaboration is to more openly acknowledge the tensions, barriers, and "elephants in the room" that often surface in crossdisciplinary efforts and to work jointly toward addressing them. Providing greater clarity on the diversity of ontological, epistemological, and philosophical perspectives that underpin the social sciences, and their implications for understanding humanenvironment relationships and crossdisciplinary social-ecological resilience research, paves the way for increased understanding and engagement. Additional insights and practical recommendations for building stronger collaborations and integration across disciplines and other perspectives can also be valuably drawn upon (e.g., Stember 1991, Buanes and Jentoft 2009, Balvanera et al. 2017, Bennett et al. 2017a, b). With regard to internal social science debates and concerns raised by social scientists concerning social-ecological resilience concepts and applications, the sharing of discordances and dissensions provides a way for the social sciences to play a disruptive and generative role that can contribute to new ways of thinking about resilience and innovative actions toward a more sustainable future. This necessitates careful consideration about how these are communicated to avoid creating or further entrenching ideological barriers that will impede effective crossdisciplinary dialog and collaboration.

The effectiveness of social-ecological resilience in informing transitions to more sustainable futures, however, requires more than enhanced collaboration and understanding across scientific disciplines. Popa et al.'s (2015) proposal for a "reflexive sustainability science" argues for combining conventional transdisciplinary approaches with reflexive, open-ended, actionoriented, transformative approaches. Transformations toward sustainability, social innovation, ingenuity, and flexibility are key areas of social-ecological resilience inquiry and analyses (e.g., Westley et al. 2013, Bousquet et al. 2016, Folke et al. 2016, Olsson et al. 2017), yet resilience researchers - from all disciplinary orientations - have yet to fully explore the role they, and the field more broadly, can play as embedded actors in transformational transition pathways. Adopting a reflexive transdisciplinary approach entails a fundamental reconceptualization of the role of science, one where scientists and scientific knowledge are understood as part of a much broader constellation of actors, voices, and knowledge needed for moving toward a more sustainable and just world. It also entails disciplines "to reimagine themselves, their methods, and their 'worlds' if they are to work productively in the twenty-first century where social relations appear increasingly complex, elusive, ephemeral, and unpredictable" (Law and Urry 2004 in reference to the social sciences). Underpinning reflexive transdisciplinary approaches are collective processes of problem framing and solutions, interrogation of normative assumptions, pluralism, experimentation, and learning (Fazey et al. 2018). Exploring such approaches in the field of social-ecological resilience, alongside other modes of knowledge exchange and collaboration, can contribute to making social-ecological resilience robust as a theoretical construct, useful in informing effective and appropriate management tools and approaches, and effective in bringing positive outcomes for 
both ecosystems and the people that inhabit them. At the end of the day, more inclusive and integrative social-ecological resilience science and practices will enable more socially appropriate and just and ecologically effective pathways for desirable transformation.

Responses to this article can be read online at: http://www.ecologyandsociety.org/issues/responses. php/10008

\section{Acknowledgments:}

We would like to thank the authors of the articles in this Special Feature, without whom this endeavor would not have been possible. This Special Feature was supported by a CSIRO Office of the Executive Payne-Scott Award and funding from CSIRO Sustainable Ecosystems' Building Resilient Australian Biodiversity Assets (BRABA) theme and CSIRO Land and Water's Adaptive Urban and Social Systems (AUSS) Program and Great Barrier Reef Coordination Project.

\section{LITERATURE CITED}

Apgar, M. J., W. Allen, K. Moore, and J. Ataria. 2015. Understanding adaptation and transformation through indigenous practice: the case of the Guna of Panama. Ecology and Society 20(1): 45. http://dx.doi.org/10.5751/ES-07314-200145

Balvanera, P., T. M. Daw, T. Gardner, B. Martín-López, A. Norström, C. Ifejika Speranza, M. Spierenburg, E. M. Bennett, M. Farfan, M. Hamann, J. N. Kittinger, T. Luthe, M. Maass, G. D. Peterson, and G. Pérez-Verdin. 2017. Key features for more successful place-based sustainability research on social-ecological systems: a Programme on Ecosystem Change and Society (PECS) perspective. Ecology and Society 22(1): 14. http://dx.doi. org/10.5751/ES-08826-220114

Bennett, N. J., R. Roth, S. C. Klain, K. Chan, P. Christie, D. A. Clark, G. Cullman, D. Curran, T. J. Durbin, G. Epstein, A. Greenberg, M. P. Nelson, J. Sandlos, R. Stedman, T. L. Teel, R. Thomas, D. Veríssimo, and C. Wyborn. 2017a. Conservation social science: understanding and integrating human dimensions to improve conservation. Biological Conservation 205:93-108. http://dx.doi.org/https://doi.org/10.1016/j.biocon.2016.10.006

Bennett, N. J., R. Roth, S. C. Klain, K. M. A. Chan, D. A. Clark, G. Cullman, G. Epstein, M. P. Nelson, R. Stedman, T. L. Teel, R. E. W. Thomas, C. Wyborn, D. Curran, A. Greenberg, J. Sandlos, and D. Veríssimo. 2017b. Mainstreaming the social sciences in conservation. Conservation Biology 31:56-66. http://dx.doi.org/ https://doi.org/10.1111/cobi.12788

Berkes, F., J. Colding, and C. Folke, editors. 2008. Navigating social-ecological systems: building resilience for complexity and change. Cambridge University Press, Cambridge, UK. http://dx. doi.org/10.1017/CBO9780511541957

Berkes, F., and C. Folke, editors. 1998. Linking social and ecological systems: management practices and social mechanisms for building resilience. Cambridge University Press, New York, New York, USA.
Bjordam, T. 2012. Critical transitions (the movie). [online] URL: https://vimeo.com/51029828

Boonstra, W. J. 2016. Conceptualizing power to study socialecological interactions. Ecology and Society 21(1): 21. http://dx. doi.org/10.5751/ES-07966-210121

Bousquet, F., A. Botta, L. Alinovi, O. Barreteau, D. Bossio, K. Brown, P. Caron, M. D'Errico, F. DeClerck, H. Dessard, E. Enfors, Kautsky, C. Fabricius, C. Folke, L. Fortmann, B. Hubert, D. Magda, R. Mathevet, R. B. Norgaard, A. Quinlan, and C. Staver. 2016. Resilience and development: mobilizing for transformation. Ecology and Society 21(3): 40. http://dx.doi. org/10.5751/ES-08754-210340

Brondizio, E. S., K. O’Brien, X. Bai, F. Biermann, W. Steffen, F. Berkhout, C. Cudennec, M. C. Lemos, A. Wolfe, J. PalmaOliveira, and C.-T. A. Chen. 2016. Re-conceptualizing the Anthropocene: a call for collaboration. Global Environmental Change 39:318-327. http://dx.doi.org/10.1016/j.gloenvcha.2016.02.006

Brown, K. 2013. Global environmental change. I: A social turn for resilience? Progress in Human Geography 38: 107-117. http:// dx.doi.org/https://doi.org/10.1177/0309132513498837

Brown, K., N. Eernstman, A. R. Huke, and N. Reding 2017. The drama of resilience: learning, doing, and sharing for sustainability. Ecology and Society 22(2): 8. http://dx.doi. org/10.5751/ES-09145-220208

Brown, K., and E. Westaway. 2011. Agency, capacity, and resilience to environmental change: lessons from human development, well-being, and disasters. Annual Review of Environment and Resources 36:321-342. http://dx.doi.org/10.1146/ annurev-environ-052610-092905

Brown, V. A., J. A. Harris, and J. Y. Russell. 2010. Tackling wicked problems through transdisciplinary imagination. Earthscan, London, UK; Washington, D.C., USA.

Buanes, A., and S. Jentoft. 2009. Building bridges: institutional perspectives on interdisciplinarity. Futures 41(7):446-454. http:// dx.doi.org/10.1016/j.futures.2009.01.010

Bush, S. R., and M. J. Marschke. 2014. Making social sense of aquaculture transitions. Ecology and Society 19(3): 50. http://dx. doi.org/10.5751/ES-06677-190350

Castree, N., W. M. Adams, J. Barry, D. Brockington, B. Buscher, E. Corbera, D. Demeritt, R. Duffy, U. Felt, K. Neves, P. Newell, L. Pellizzoni, K. Rigby, P. Robbins, L. Robin, D. B. Rose, A. Ross, D. Schlosberg, S. Sorlin, P. West, M. Whitehead, and B. Wynne. 2014. Changing the intellectual climate. Nature Climate Change 4:763-768. http://dx.doi.org/10.1038/nclimate2339

Cote, M., and A. J. Nightingale. 2012. Resilience thinking meets social theory: situating social change in socio-ecological systems (SES) research. Progress in Human Geography 36:475-489. http:// dx.doi.org/10.1177/0309132511425708

Davidson, D. J. 2010. The applicability of the concept of resilience to social systems: some sources of optimism and nagging doubts. Society and Natural Resources 23:1135-1149. http://dx.doi. org/10.1080/08941921003652940

Davidson-Hunt, I., and F. Berkes. 2003. Learning as you journey: Anishinaabe perception of social-ecological environments and 
adaptive learning. Conservation Ecology 8(1): 5. http://dx.doi. org/10.5751/ES-00587-080105

Dwiartama, A., and C. Rosin. 2014. Exploring agency beyond humans: the compatibility of Actor-Network Theory (ANT) and resilience thinking. Ecology and Society 19(3): 28. http://dx.doi. org/10.5751/ES-06805-190328

Evans, J. P. 2011. Resilience, ecology and adaptation in the experimental city. Transactions of the Institute of British Geographers 36:223-237. http://dx.doi.org/10.1111/j.1475-5661.2010.00420. $\underline{\mathrm{X}}$

Fabinyi, M., L. Evans, and S. J. Foale. 2014. Social-ecological systems, social diversity, and power: insights from anthropology and political ecology. Ecology and Society 19(4): 28. http://dx.doi. org/10.5751/ES-07029-190428

Fazey, I., et al. 2018. Ten essentials for action-oriented and second order energy transitions, transformations and climate change research. Energy Research and Social Science 40:54-70. http://dx. doi.org/10.1016/j.erss.2017.11.026

Field, C. B., V. R. Barros, D. J. Dokken, K. J. Mach, M. D. Mastrandrea, T. E. Bilir, M. Chatterjee, K. L. Ebi, Y. O. Estrada, R. C. Genova, B. Girma, E. S. Kissel, A. N. Levy, S. MacCracken, P. R. Mastrandrea, and L. L. White, editors. 2014. Climate change 2014: impacts, adaptation, and vulnerability. part a: global and sectoral aspects. Working Group II Contribution to the Fifth Assessment Rrport of the Intergovernmental Panel on Climate Change. Cambridge University Press, Cambridge, UK; New York, New York, USA. [online] URL: http://www.ipcc.ch/pdf/ assessment-report/ar5/wg2/WGIIAR5-FrontMatterA FINAL.pdf.

Folke, C. 2004. Traditional knowledge in social-ecological systems. Ecology and Society 9(3): 7. [online] URL: http://www. ecologyandsociety.org/vo19/iss3/art7/

Folke, C., R. Biggs, A. V. Norström, B. Reyers, and J. Rockström. 2016. Social-ecological resilience and biosphere-based sustainability science. Ecology and Society 21(3): 41. http://dx.doi.org/10.5751/ ES-08748-210341

Goldstein, B., editor. 2012. Collaborative resilience: moving through crisis to opportunity. The MIT Press, Cambridge, Massachusetts, USA; London, UK.

Gray, S. A., S. Gray, J. L. De Kok, A. E. R. Helfgott, B. O’Dwyer, R. Jordan, and A. Nyaki. 2015. Using fuzzy cognitive mapping as a participatory approach to analyze change, preferred states, and perceived resilience of social-ecological systems. Ecology and Society 20(2): 11. http://dx.doi.org/10.5751/ES-07396-200211

Hahn, T., and B. Nykvist. 2017. Are adaptations self-organized, autonomous, and harmonious? Assessing the social-ecological resilience literature. Ecology and Society 22(1):12. http://dx.doi. org/https://doi.org/10.5751/ES-09026-220112

Hatt, K. 2013. Social attractors: a proposal to enhance "resilience thinking" about the social. Society and Natural Resources 26:3043. http://dx.doi.org/10.1080/08941920.2012.695859

Hirsch Hadorn, G., D. Bradley, C. Pohl, S. Rist, and U. Wiesmann. 2006. Implications of transdisciplinarity for sustainability research. Ecological Economics 60:119-128 http:// dx.doi.org/10.1016/j.ecolecon.2005.12.002
Hobman, E. V., and I. Walker. 2015. Stasis and change: social psychological insights into social-ecological resilience. Ecology and Society 20(1): 39. http://dx.doi.org/10.5751/ES-07260-200139

ISSC/UNESCO (International Social Science Council / United Nations Educational, Scientific and Cultural Organization). 2013. World social science report 2013: changing global environments. Organisation for Economic Co-operation and Development (OECD) Publishing and UNESCO Publishing, Paris, France. [online] URL: http://unesdoc.unesco.org/ images/0022/002246/224677e.pdf

Krauss, W. 2015. Anthropology in the Anthropocene: sustainable development, climate change and interdisciplinary research. Pages 59-76 in H. Greschke and J. Tischler, editors. Grounding global climate change: contributions from the social and cultural sciences. Springer, Dordrecht, The Netherlands. http://dx.doi. org/10.1007/978-94-017-9322-3 4

Law, J., and J. Urry. 2004. Enacting the social. Economy and Society 33:390-410. http://dx.doi.org/10.1080/0308514042000225716

Leyshon, C. 2014. Critical issues in social science climate change research. Contemporary Social Science 9:359-373. http://dx.doi. org/10.1080/21582041.2014.974890

Miller, T. R., T. D. Baird, C. M. Littlefield, G. Kofinas, F. Chapin, III, and C. L. Redman. 2008. Epistemological pluralism: reorganizing interdisciplinary research. Ecology and Society 13 (2): 46. [online] URL: http://www.ecologyandsociety.org/vol13/ iss2/art46/ http://dx.doi.org/10.5751/ES-02671-130246

Moller, H., F. Berkes, P. O. Lyver, and M. Kislalioglu. 2004. Combining science and traditional ecological knowledge: monitoring populations for co-management. Ecology and Society 9(3): 2. [online] URL: http://www.ecologyandsociety.org/vol9/ iss3/art2/ http://dx.doi.org/10.5751/ES-00675-090302

Moon, K., and D. Blackman. 2014. A guide to understanding social science research for natural scientists. Conservation Biology 28:1167-1177. http://dx.doi.org/10.1111/cobi.12326

Moore, M.-L., O. Tjornbo, E. Enfors, C. Knapp, J. Hodbod, J. A. Baggio, A. Norström, P. Olsson, and D. Biggs. 2014. Studying the complexity of change: toward an analytical framework for understanding deliberate social-ecological transformations. Ecology and Society 19(4): 54. http://dx.doi.org/10.5751/ ES-06966-190454

Olsson, L., A. Jerneck, H. Thoren, J. Persson, and D. O'Byrne. 2015. Why resilience is unappealing to social science: theoretical and empirical investigations of the scientific use of resilience. Science Advances 1(4): e1400217. http://dx.doi.org/10.1126/ $\underline{\text { sciadv. } 1400217}$

Olsson, P., M.-L. Moore, F. R. Westley, and D. D. P. McCarthy. 2017. The concept of the Anthropocene as a game-changer: a new context for social innovation and transformations to sustainability. Ecology and Society 22(2): 31. http://dx.doi. org/10.5751/ES-09310-220231

Phelan, L., A. Henderson-Sellers, and R. Taplin. 2012. The political economy of addressing the climate crisis in the Earth system: undermining perverse resilience. New Political Economy 18:198-226. http://dx.doi.org/10.1080/13563467.2012.678820 
Popa, F., M. Guillermin, and T. Dedeurwaerdere. 2015. A pragmatist approach to transdisciplinarity in sustainability research: from complex systems theory to reflexive science. Futures 65:45-56. http://dx.doi.org/10.1016/j.futures.2014.02.002

Rathwell, K. J., and D. Armitage. 2016. Art and artistic processes bridge knowledge systems about social-ecological change: an empirical examination with Inuit artists from Nunavut, Canada. Ecology and Society 21(2): 21. http://dx.doi.org/10.5751/ ES-08369-210221

Stember, M. 1991. Advancing the social sciences through the interdisciplinary enterprise. The Social Science Journal 28:1-14. http://dx.doi.org/10.1016/0362-3319(91)90040-B

Stone-Jovicich, S. 2015. Probing the interfaces between the social sciences and social-ecological resilience: insights from integrative and hybrid perspectives in the social sciences. Ecology and Society 20(2): 25. http://dx.doi.org/10.5751/ES-07347-200225

Tidball, K. G. 2014. Seeing the forest for the trees: hybridity and social-ecological symbols, rituals and resilience in postdisaster contexts. Ecology and Society 19(4): 25. http://dx.doi.org/10.5751/ ES-06903-190425

Viseu, A. 2015. Integration of social science into research is crucial. Nature 525: 291. http://dx.doi.org/10.1038/525291a

Westley, F. R., O. Tjornbo, L. Schultz, P. Olsson, C. Folke, B. Crona and Ö. Bodin. 2013. A theory of transformative agency in linked social-ecological systems. Ecology and Society 18(3): 27. http://dx.doi.org/10.5751/ES-05072-180327

Wilkinson, C. 2012. Social-ecological resilience: insights and issues for planning theory. Planning Theory 11(2): 148-169. http:// dx.doi.org/10.1177/1473095211426274 